ASTHMA

\title{
External validity of randomised controlled trials in asthma: to whom do the results of the trials apply?
}

\author{
Justin Travers, Suzanne Marsh, Mathew Williams, Mark Weatherall, Brent Caldwell, Philippa \\ Shirtcliffe, Sarah Aldington, Richard Beasley
}

Thorax 2007:62:219-223. doi: 10.1136/thx.2006.066837

\begin{abstract}
See end of article for authors' affiliations

......................

Correspondence to: Professor R Beasley, Medical Research Institute of New Zealand, PO Box 10055 Wellington, New Zealand; richard.beasley@mrinz.ac. $\mathrm{nz}$
\end{abstract}

Received 12 June 2006

Accepted 9 October 2006

Published Online First

13 November 2006

\begin{abstract}
Background: Asthma is a heterogeneous disease with a wide range of clinical phenotypes, not all of which may be encompassed in the subjects included in randomised controlled trials (RCTs). This makes it difficult for clinicians to know to what extent the evidence derived from RCTs applies to a given patient.

Aim: To calculate the proportion of individuals with asthma who would have been eligible for the major asthma RCTs from the data of a random community survey of respiratory health.

Methods: A postal survey was sent to 3500 randomly selected individuals aged 25-75 years. Respondents were invited to complete a detailed respiratory questionnaire and pulmonary function testing. Participants with current asthma were assessed against the eligibility criteria of the 17 major asthma RCTs cited in the Global Initiative for Asthma (GINA) guidelines.

Findings: A total of 749 participants completed the full survey, of whom 179 had current asthma. A median $4 \%$ of participants with current asthma (range $0-36 \%$ ) met the eligibility criteria for the included RCTs. A median $6 \%$ (range $0-43 \%$ ) of participants with current asthma on treatment met the eligibility criteria. Interpretation: This study shows that the major asthma RCTs on which the GINA guidelines are based may have limited external validity as they have been performed on highly selected patient populations. Most of the participants with current asthma on treatment in the community would not have been eligible for these RCTs.
\end{abstract}

! $\mathrm{n}$ recent years, clinical decision making has been directed away from the doctor's clinical experience towards a paradigm based on the evidence from randomised controlled trials (RCTs). The results of large RCTs have been translated into guidelines containing evidence-graded recommendations, which the clinicians are encouraged to accept as the basis of good clinical practice. However, RCTs are only able to guide clinical decision making when trials are well designed, have clinically relevant outcome measures and the subjects in the trial are representative of the range of real-life patients managed by the doctor. ${ }^{1}$ This last requirement is not always met, and it is recognised that older adults, women and ethnic minorities may be under-represented in RCTs. ${ }^{2-5}$ Design considerations often lead to RCTs that are performed in highly selected patient populations, such as those with the most typical features of a disease or those most likely to respond to the intervention being studied. This may be necessary to initially assess the efficacy of an intervention-for example, in a phase II clinical trial. However, when these same design considerations are applied to phase III and IV clinical trials, they may result in the exclusion of many subjects in whom treatment may be potentially useful, ${ }^{1}$ thereby restricting the generalisability of the trial results.

Asthma is a heterogeneous disease with a wide range of clinical phenotypes, ${ }^{6}$ hence, it is not surprising that there is evidence that many individuals with asthma are not eligible for RCTs owing to highly selective inclusion and exclusion criteria. ${ }^{78}$ This makes it difficult for clinicians to know to what extent the evidence for the safety and effectiveness of an intervention applies to a given individual. The proportion of individuals with asthma who are eligible for the major asthma RCTs from which the clinical evidence is derived is not known. In this population-based survey of respiratory health, we determined the proportion of individuals with asthma who would have met the eligibility criteria for the RCTs that form the basis of asthma consensus guidelines.

\section{METHODS}

\section{Participants}

Data of the participants were obtained from the results of the Wellington Respiratory Survey, a detailed survey of respiratory health performed between 2002 and 2005 in Wellington, New Zealand. ${ }^{9}$ Participants were recruited from a postal questionnaire sent to 3500 individuals randomly selected from the electoral register. Random selection was performed so that equal numbers of questionnaires were sent to men and women in each of the five-decade age groups between the ages of 25 and 75 years. Participants who responded to the postal questionnaire were invited to undertake the full survey that included a detailed, interviewer administered questionnaire, pulmonary function tests, chest CT scan, skin-prick tests to common allergens, blood tests for eosinophil count and serum immunoglobulin E and a l week peak flow diary.

\section{Pulmonary function testing}

Pulmonary function tests were carried out using two Jaeger Master Screen Body volume constant plethysmography units with a pneumotachograph (Masterlab 4.5 and 4.6 Erich-Jaeger, Wurzberg, Germany) as described previously. ${ }^{9}$ Static and dynamic lung volumes were measured before and after giving $400 \mu \mathrm{g}$ of salbutamol via a spacer device. Peak flow readings were recorded by participants twice daily over a 1 week period following instructions in the use of a Breath Alert peak flow meter (Medical Developments International, Melbourne, Australia). Participants were not tested within 3 weeks of an upper or lower respiratory tract infection. The survey was approved by the Wellington Ethics Committee, and written informed consent was obtained from each participant.

Abbreviations: COPD, chronic obstructive pulmonary disease; $\mathrm{FEV}_{1}$, forced expiratory volume in $1 \mathrm{~s}$; GINA, Global Initiative for Asthma; RCT, randomised controlled trial 


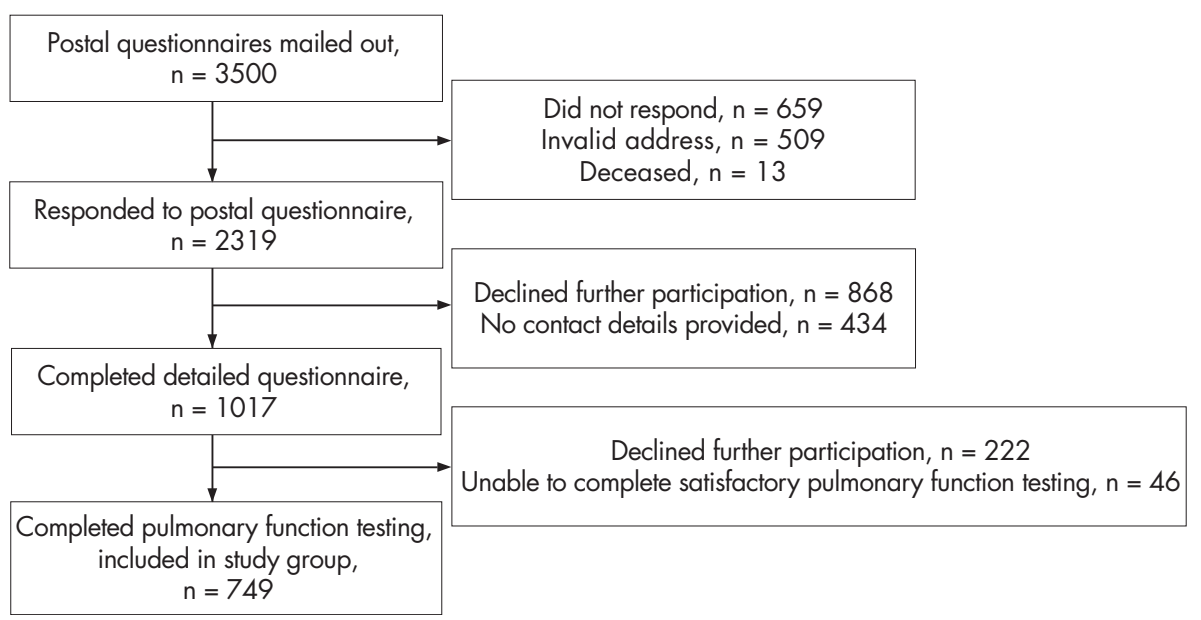

Figure 1 Flow diagram of the Wellington Respiratory Survey.

\section{Identification of current asthma}

Participants were identified as having "current asthma" if they:

- reported asthma diagnosed by a doctor and either symptoms of asthma or use of drugs for asthma in the previous 12 months,

- showed an increase in the forced expiratory volume in $1 \mathrm{~s}$ $\left(\mathrm{FEV}_{1}\right) \geqslant 15 \%$ compared with baseline after bronchodilator administration, and/or

- documented diurnal peak flow variation of $\geqslant 20 \%$ in any of the first 7 days of recordings.

Symptoms of asthma were wheeze, shortness of breath and wheeze at night or chest tightness at night. A participant with current asthma was identified as having "current asthma on treatment" if they reported the use of drugs for asthma in the previous 12 months.

\section{Identification of RCTs}

Asthma RCTs were identified in a systematic manner. ${ }^{10}$ To qualify as a trial forming the basis of consensus guidelines, an

Table 1 Characteristics of participants with current asthma $(n=179)$

\begin{tabular}{|c|c|}
\hline & Mean (SD) \\
\hline Age (years) & $55.2(13.6)$ \\
\hline \multirow[t]{2}{*}{$\begin{array}{l}\mathrm{FEV} \text { pre-bronchodilator as a percentage } \\
\text { of predicted }\end{array}$} & $77.8(21.8)$ \\
\hline & n (\%) \\
\hline Women & 87 (49) \\
\hline Smoker* & $54(30)$ \\
\hline Asthma diagnosed by doctor & $137(77)$ \\
\hline Current symptoms ${ }^{\prime}$ & $122(68)$ \\
\hline $\begin{array}{l}\text { Any drug for asthma used in the } \\
\text { previous } 12 \text { months }\end{array}$ & $127(71)$ \\
\hline $\begin{array}{l}\text { Inhaled corticosteroid use in the } \\
\text { previous } 12 \text { months }\end{array}$ & $93(52)$ \\
\hline $\begin{array}{l}\text { Inhaled short-acting } \beta \text {-agonist use in the } \\
\text { previous } 12 \text { months }\end{array}$ & $114(64)$ \\
\hline COPD $\ddagger$ & 67 (37) \\
\hline Peak flow variability $\geqslant 20 \%$ & 61 (34) \\
\hline Bronchodilator reversibility $\geqslant 15 \%$ & $43(24)$ \\
\hline \multicolumn{2}{|c|}{$\begin{array}{l}\text { COPD, chronic obstructive pulmonary disease; } \mathrm{FEV}_{1} \text {, forced expiratory } \\
\text { volume in } 1 \mathrm{~s} \text {. } \\
{ }^{*} \text { Current or ex-smoker with }>10 \text { pack-years of exposure to cigarette } \\
\text { smoke. } \dagger \text { Wheeze, shortness of breath and wheeze at night or chest tightness } \\
\text { at night in the past year. } \\
\neq \text { Defined as a FEV } 1 \text { /forced vital capacity ratio }<0.7 \text { after bronchodilator. }{ }^{12}\end{array}$} \\
\hline
\end{tabular}

RCT had to be cited as a reference accompanying a level A or B evidence-graded treatment recommendation in the Global Initiative for Asthma (GINA) Workshop Guideline 'Global strategy for asthma management and prevention: 2005 Update'.$^{11}$ Trials had to be RCTs of drug treatment for asthma in adults, with at least 400 participants randomised, and have been published in the past 30 years. References were assessed independently by two reviewers (JT, BC). Inclusion and exclusion criteria were obtained from the full text of all qualifying trials.

\section{Analysis}

The proportion of participants with current asthma who met the eligibility criteria for each of the identified RCTs was determined. Whenever we were unable to determine whether a participant met a particular RCT eligibility criterion from our survey data, the participant was considered to have met that criterion. For example, an RCT may have a criterion that participants be free from exacerbations in the previous 2 months, when our survey recorded only that participants were exacerbation free in the past 3 weeks. In this case, all participants who were exacerbation free for 3 weeks were considered to meet this criterion and remain potentially eligible.

The sponsor had no involvement in the study design, collection, analysis interpretation of data, the writing of the report or the decision to submit for publication.

\section{RESULTS}

A total of 2319 participants responded to the postal survey, representing a response rate of $78 \%$. Of these respondents, 749 participants completed the detailed questionnaire and satisfactory pulmonary function testing, and formed the study group (fig 1). Compared with the 1570 survey respondents who were not included in the study group, the study group had a higher rate of asthma diagnosed by the doctor $(23.1 \% v 17.3 \%)$, more men $(53.7 \% v 44.3 \%)$ and ex-smokers (41.4\% v 35.3\%). There were no significant differences in the prevalence of chronic bronchitis or emphysema diagnosed by a doctor.

Of the 749 participants in the study group, 179 (24\%) met our criteria for current asthma and 127 (17\%) met our criteria for current asthma on treatment. Among the 179 participants with current asthma, 67 also met the criteria for chronic obstructive pulmonary disease (COPD), defined as an $\mathrm{FEV}_{\mathrm{l}} /$ forced vital capacity ratio $<0.7$ postbronchodilator. ${ }^{12}$ Of these 67 participants, 29 had a tobacco cigarette history of $>10$ pack-years. 


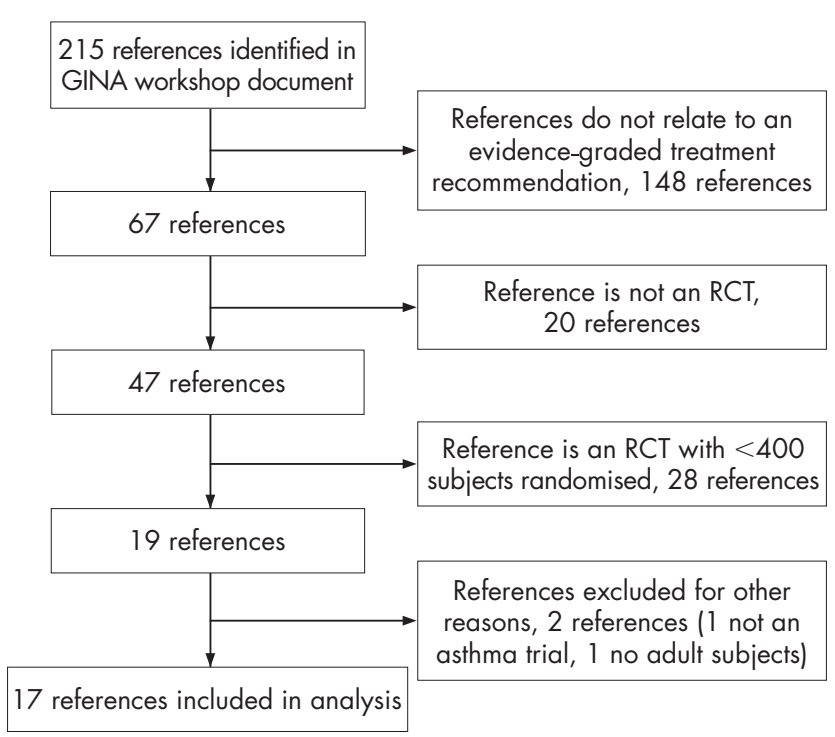

Figure 2 Flow diagram for the selection of randomised controlled trials (RCTs). GINA, Global Initiative for Asthma.

Table 1 presents the characteristics of the participants with current asthma.

There were 215 individual references in the relevant chapter of the GINA guidelines, from which 17 qualifying RCTs were identified and included in the analysis (fig 2). ${ }^{13-29}$ Table 2 gives the characteristics of the included RCTs. The number of participants screened was stated in 8 of the 17 RCTs included in the analysis.

Inclusion criteria used in all 17 RCTs were a diagnosis of asthma, age greater than a lower age limit and bronchodilator reversibility. Other inclusion criteria were a specified $\mathrm{FEV}_{1}$ range in 16, specified inhaled corticosteroid use in 12, specified symptoms or use of rescue drugs in 9, age less than an upper age limit in 7, peak flow variability in 4 and other inclusion criteria in 4 RCTs. Exclusion criteria used were recent respiratory tract infection or asthma exacerbation in 13, potentially confounding use of drugs in 11 , comorbid conditions in 9, more than a specified amount of smoking in 7 , pregnant or lactating female participants in 5 and other exclusion criteria in 6 RCTs.

The proportion of participants with current asthma who met the eligibility criteria for these 17 RCTs ranged from $0 \%$ to $36 \%$, with a median of $4 \%$ (table 3 ). The proportion of participants with current asthma on treatment who met the eligibility criteria for these trials ranged from $0 \%$ to $43 \%$, with a median of $6 \%$ (table 3 ).

Table 4 shows the proportion of participants with current asthma who did not meet common eligibility criteria. The most selective criterion was bronchodilator reversibility, which excluded either $71 \%$ or $76 \%$ of participants with current asthma, depending on whether $12 \%$ or $15 \%$ reversibility in $\mathrm{FEV}_{1}$ was required. The requirement for peak flow variability of $\geqslant 20 \%$ resulted in the exclusion of $66 \%$ of participants with current asthma.

\section{DISCUSSION}

This study shows that the major asthma RCTs have been performed on highly selected patient populations, with a median of only $4 \%$ of participants with current asthma in our community being eligible. Similarly, a median of only $6 \%$ of participants with current asthma on treatment would have been eligible for these RCTs. These findings suggest that although the treatment recommendations of major asthma guidelines have a strong scientific evidence base, they may be limited with respect to the external validity of the RCTs from which they are derived.

We made no attempt to perform a complete search of the asthma literature, and probably RCTs have been reported elsewhere that are more inclusive of participants with current asthma than those examined. However, the RCTs selected here are those that provide the evidence for the treatment recommendations of the GINA guidelines, ${ }^{11}$ and hence have a direct effect on asthma management worldwide. Using actual RCTs rather than a hypothetical "typical' $\mathrm{RCT}^{7}$ has allowed a realistic estimate of the degree of selectivity of existing asthma trials. It also allows comparison of the degree of selectivity between different drugs for asthma or drug indications-for example, there was only one qualifying RCT comparing theophylline with another agent, for which none of the 179 participants with current asthma in our study were eligible. ${ }^{17}$

Table 2 Characteristics of included randomised controlled trials

\begin{tabular}{|c|c|c|c|c|c|}
\hline Reference & Year & $\begin{array}{l}\text { Participants screened } \\
\text { (n) }\end{array}$ & $\begin{array}{l}\text { Participants randomised } \\
\text { (n) }\end{array}$ & $\begin{array}{l}\text { Age range } \\
\text { (years) }\end{array}$ & Interventions \\
\hline Greening et $a l^{13}$ & 1994 & Not stated & 429 & $>18$ & Salmeterol/BDP $v$ higher-dose BDP \\
\hline Woolcock et $a l^{14}$ & 1996 & 990 & 738 & $>17$ & $\begin{array}{l}\text { Salmeterol/BDP (2 different salmeterol doses) } v \text { higher-dose } \\
\text { BDP }\end{array}$ \\
\hline Pauwels et al ${ }^{15}$ & 1997 & 1114 & 852 & $18-70$ & $\begin{array}{l}\text { Formoterol/budesonide } v \text { budesonide ( } 2 \text { different } \\
\text { budesonide doses in each group) }\end{array}$ \\
\hline Busse et all ${ }^{16}$ & 1998 & Not stated & 473 & $18-70$ & Budesonide (4 different doses) $\vee$ placebo \\
\hline Reed et al ${ }^{7}$ & 1998 & Not stated & 747 & $6-65$ & BDP $v$ theophylline \\
\hline Wenzel et al ${ }^{8}$ & 1998 & Not stated & 539 & $>12$ & Salmeterol $v$ albuterol \\
\hline Laviolette et al ${ }^{19}$ & 1999 & Not stated & 642 & $>15$ & Montelukast/BDP $v$ montelukast $v$ BDP $v$ placebo \\
\hline Bleecker et $a P^{p o}$ & 2000 & 592 & 451 & $>12$ & Fluticasone $v$ zafirlukast \\
\hline Nelson et $a f^{1}$ & 2000 & Not stated & 447 & $>15$ & Salmeterol/fluticasone $v$ montelukast/fluticasone \\
\hline Busse et $a P^{2}$ & 2001 & Not stated & 525 & $12-75$ & Omalizumab v placebo \\
\hline Fish et $a^{p^{3}}$ & 2001 & Not stated & 948 & $>15$ & Salmeterol $v$ montelukast \\
\hline $\mathrm{O}^{\prime}$ Byrne et $a^{p^{4}}$ & 2001 & 2525 & 1970 & $>12$ & $\begin{array}{l}\text { Formoterol/budesonide } v \text { budesonide } v \text { placebo and } \\
\text { formoterol/budesonide } v \text { budesonide ( } 2 \text { different } \\
\text { budesonide doses in each group) }\end{array}$ \\
\hline Lalloo et a ${ }^{5}$ & 2003 & 494 & 467 & $>15$ & Formoterol/budesonide $v$ higher-dose budesonide \\
\hline Pauwels et af ${ }^{26}$ & 2003 & Not stated & 7241 & $5-66$ & Budesonide $v$ placebo \\
\hline Price ef $a p^{7}$ & 2003 & 1192 & 889 & $15-75$ & Montelukast/budesonide $v$ higher-dose budesonide \\
\hline Ringdal et a ${ }^{8}$ & 2003 & 1168 & 806 & $>15$ & Salmeterol/fluticasone $v$ montelukast/fluticasone \\
\hline Vaquerizo et a ${ }^{p q}$ & 2003 & 846 & 639 & $18-70$ & Montelukast/budesonide $v$ budesonide \\
\hline
\end{tabular}

BDP, beclomethasone dipropionate. 
Table 3 Percentage of individuals who potentially meet eligibility criteria for included asthma randomised controlled trials

\begin{tabular}{llc}
\hline $\begin{array}{l}\text { RCT } \\
\text { reference }\end{array}$ & $\begin{array}{l}\text { Current asthma }(\%), \\
\mathbf{n = 1 7 9}\end{array}$ & $\begin{array}{l}\text { Current asthma on } \\
\text { treatment }(\%), \mathbf{n = 1 2 7}\end{array}$ \\
\hline 13 & 5 & 7 \\
14 & 7 & 10 \\
15 & 6 & 9 \\
16 & 6 & 8 \\
17 & 0 & 0 \\
18 & 4 & 6 \\
19 & 2 & 3 \\
20 & 1 & 1 \\
21 & 7 & 9 \\
22 & 8 & 11 \\
23 & 7 & 9 \\
24 & 36 & 43 \\
25 & 2 & 2 \\
26 & 1 & 0 \\
27 & 1 & 2 \\
28 & 2 & 3 \\
29 & 3 & 5 \\
\hline \multirow{2}{*}{ RCT, randomised controlled trial. } &
\end{tabular}

We were not always able to determine from our survey data whether a subject with asthma met a particular criterion, as many trials used criteria for exacerbations, symptom scores and measures of drug use that we were not able to duplicate. Where this occurred, participants were deemed to remain eligible by the criterion we could not assess. Hence, our estimates of the proportion of participants with asthma eligible for a given trial are maximum values, and the true degree of selectivity of these RCTs is probably greater than we have shown.

Our definition of asthma did not exclude those with concomitant COPD, defined as a post-bronchodilator $\mathrm{FEV}_{1}$ / forced vital capacity $<0.7 .{ }^{12}$ About one third of the participants with asthma met these criteria, most of whom did not have a significant smoking history. As a result, it is probable that this group with concomitant COPD was predominantly made up of participants with asthma, who had developed an irreversible component to their airway obstruction. Importantly, they represented a group of participants that had mostly received a doctor's diagnosis of asthma and had been prescribed asthma treatment based on trials that largely excluded them.

The most common reason that participants with current asthma were not able to meet RCT eligibility criteria was the need to show bronchodilator reversibility. Application of this criterion resulted in only about a quarter of participants with current asthma in our survey being eligible for the RCTs included in the study. This proportion was greater than that observed from a similar study from Australia, in which only 7$18 \%$ of participants with current asthma showed bronchodilator reversibility depending on the criteria used. ${ }^{30}$ These observations are likely to be due to the widespread use of inhaled corticosteroid treatment, resulting in good asthma control and associated reduction in lung function variability in asthma. The use of bronchodilator reversibility criteria in asthma RCTs may be justified on the basis that it provides the greatest opportunity to determine the maximum efficacy of a therapeutic agent. It also identifies individuals who do not have optimal asthma control, and as a result could be considered suitable for the addition of another therapeutic agent. This has led to novel study designs in which participants reduce or withdraw their inhaled corticosteroid treatment to demonstrate unstable asthma and its associated lung function variability. ${ }^{31} 32$

Other eligibility criteria, such as the requirement that participants be non-smokers, also tend to produce a more
Table 4 Selectivity of eligibility criteria

\begin{tabular}{ll}
\hline Criterion & $\begin{array}{l}\text { Participants with current } \\
\text { asthma excluded }(\%)\end{array}$ \\
\hline Bronchodilator reversibility $\geqslant 15 \%$ & 76 \\
Bronchodilator reversibility $\geqslant 12 \%$ & 71 \\
Peak flow variability $\geqslant 20 \%$ & 66 \\
FEV $1 \geqslant 50 \%$ and $<80 \%$ of predicted & 61 \\
Inhaled corticosteroid use & 48 \\
$<10$ pack-years of exposure to cigarette & 31 \\
Active symptoms or use of rescue drugs & 20 \\
FEV $1 \geqslant 50 \%$ of predicted & 12 \\
\hline
\end{tabular}

homogeneous study population. This has the advantage of reducing the likelihood of a participant having concomitant COPD and limiting the number of variables apart from the RCT intervention, again maximising the likelihood of demonstrating a therapeutic effect specific to asthma. However, the criterion that participants be non-smokers resulted in the exclusion of $30 \%$ of the participants with current asthma in our study, representing a major group in which drug efficacy would not have been assessed. The importance of this limitation is evident from the experience with inhaled corticosteroids in asthma, where the studies showing a reduced efficacy of inhaled corticosteroids in smokers were not undertaken until $>25$ years after the introduction of these agents. ${ }^{33}{ }^{34}$

In our study group, the prevalence of wheezing and asthma diagnosed by a doctor was relatively high, with rates of $28.8 \%$ and $23.1 \%$, respectively. These findings reflect the high prevalence of asthma in the New Zealand population, consistent with previous surveys that have reported rates of wheezing between $26 \%$ and $30 \%{ }^{35-37}$ Owing to the high survey response rate and the similarity between survey responders and the study group that undertook the investigative procedures, any effect of non-response bias is likely to be small.

In summary, we conclude that the degree to which the results from asthma RCTs apply to individual patients cannot be assessed directly and the clinician cannot assume that their patient will respond to a drug in the same way as trial participants. As a result, clinicians should consider that the treatment recommendations of major asthma guidelines may be limited with respect to the external validity of the RCTs on which they are based. This does not mean that the results of these RCTs are not generalisable to the wider community of individuals with asthma, but rather that the degree of generalisability is uncertain. We encourage the inclusion of a wider range of participants with asthma in future clinical trials.

\section{Authors' affiliations}

Justin Travers, Suzanne Marsh, Mathew Williams, Brent Caldwell, Philippa Shirtcliffe, Sarah Aldington, Medical Research Institute of New Zealand, Wellington, New Zealand

Mark Weatherall, Wellington School of Medicine and Health Sciences, Wellington, New Zealand

Richard Beasley, University of Southampton, Southampton, UK

Funding: The Wellington Respiratory Survey was funded by GlaxoSmithKline UK.

Competing interests: Richard Beasley is a member of the GINA Assembly.

\section{REFERENCES}

1 Rothwell PM. External validity of randomised controlled trials: "to whom do the results of this trial apply? " Lancet 2005:365:82-93.

2 Hutchins LF, Unger JM, Crowley JJ, et al. Underrepresentation of patients 65 years of age or older in cancer-treatment trials. N Engl J Med 1999:341:2061-7.

3 Ramasubbu K, Gurm H, Litaker D. Gender bias in clinical trials: do double standards still apply? J Womens Health Gend Based Med 2001;10:757-64. 
4 Heiat A Gross CP, Krumholz HM Representation of the elderly, women, and minorities in heart failure clinical trials. Arch Intern Med 2002;162:1682-8.

5 Jha P, Deboer D, Sykora K, et al. Characteristics and mortality outcomes of thrombolysis trial participants and nonparticipants: a population-based comparison. J Am Coll Cardiol 1996;27:1335-42.

6 Bel EH. Clinical phenotypes of asthma. Curr Opin Pulm Med 2004;10:44-50

7 Herland K, Akselsen JP, Skjonsberg OH, et al. How representative are clinical study patients with asthma or COPD for a larger "real life" population of patients with obstructive lung disease? Respir Med 2005:99:11-19.

8 Storms W. Clinical trials: are these your patients? J Allergy Clin Immunol 2003;112(5 Suppl):S107-11.

9 Marsh S, Aldington S, Williams MV, et al. Physiological associations of computerized tomography lung density: a factor analysis. Int J COPD 2006;1:181-7.

10 Moher D, Cook DJ, Eastwood S, et al. Improving the quality of reports of metaanalyses of randomised controlled trials: the QUOROM statement. Quality of Reporting of Meta-analyses. Lancet 1999;354:1896-900.

11 Global Initiative for Asthma. Establish medical plans for long-term asthma management in adults. Global strategy for asthma management and prevention. NIH Publication Number 02-3659. Updated 2005 from the 2004 document. http://www.ginasthma.org (accessed 16 Dec 2006).

12 Global Initiative for Chronic Obstructive Lung Disease. Global strategy for the diagnosis, management, and prevention of chronic obstructive pulmonary disease, Updated 2005 (based on an April 1998 NHLBI/WHO Workshop).http://www.goldcopd.com (accessed 16 Dec 2006).

13 Greening AP, Ind PW, Northfield M, et al. Added salmeterol versus higher-dose corticosteroid in asthma patients with symptoms on existing inhaled corticosteroid. Allen \& Hanburys Limited UK Study Group. Lance 1994;344:219-24.

14 Woolcock A, Lundback B, Ringdal N, et al. Comparison of addition of salmeterol to inhaled steroids with doubling of the dose of inhaled steroids. Am J Respir Crit Care Med 1996;153:1481-8.

15 Pauwels RA, Lofdahl CG, Postma DS, et al. Effect of inhaled formoterol and budesonide on exacerbations of asthma. Formoterol and Corticosteroid Establishing Therapy (FACET) International Study Group. N Engl J Med 1997;337:1405-11

16 Busse WW, Chervinsky P, Condemi J, et al. Budesonide delivered by Turbuhaler is effective in a dose-dependent fashion when used in the treatment of adult patients with chronic asthma. J Allergy Clin Immunol 1998;101(Pt 1):457-63.

17 Reed CE, Offord KP, Nelson HS, et al. Aerosol beclomethasone dipropionate spray compared with theophylline as primary treatment for chronic mild-tomoderate asthma. The American Academy of Allergy, Asthma and Immunology Beclomethasone Dipropionate-Theophylline Study Group. J Allergy Clin Immunol 1998; 101(Pt 1):14-23

18 Wenzel SE, Lumry W, Manning M, et al. Efficacy, safety, and effects on quality of life of salmeterol versus albuterol in patients with mild to moderate persistent asthma. Ann Allergy Asthma Immunol 1998;80:463-70.

19 Laviolette M, Malmstrom K, Lu S, et al. Montelukast added to inhaled beclomethasone in treatment of asthma. Montelukast/Beclomethasone Additivity Group. Am J Respir Crit Care Med 1999;160:1862-8.
20 Bleecker ER, Welch MJ, Weinstein SF, et al. Low-dose inhaled fluticasone propionate versus oral zafirlukast in the treatment of persistent asthma. J Allergy Clin Immunol 2000; 105(Pt 1):1123-9.

21 Nelson HS, Busse WW, Kerwin E, et al. Fluticasone propionate/salmeterol combination provides more effective asthma control than low-dose inhaled corticosteroid plus montelukast. J Allergy Clin Immunol 2000;106:1088-95.

22 Busse W, Corren J, Lanier BQ, et al. Omalizumab, anti-lgE recombinant humanized monoclonal antibody, for the treatment of severe allergic asthma. J Allergy Clin Immunol 2001;108:184-90.

23 Fish JE, Israel E, Murray JJ, et al. Salmeterol powder provides significantly better benefit than montelukast in asthmatic patients receiving concomitant inhaled corticosteroid therapy. Chest 2001;120:423-30.

24 O'Byrne PM, Barnes PJ, Rodriguez-Roisin R, et al. Low dose inhaled budesonide and formoterol in mild persistent asthma: the OPTIMA randomised trial. Am J Respir Crit Care Med 2001;164(Pt 1):1392-7.

25 Lalloo UG, Malolepszy J, Kozma D, et al. Budesonide and formoterol in a single inhaler improves asthma control compared with increasing the dose of corticosteroid in adults with mild-to-moderate asthma. Chest 2003;123:1480-7.

26 Pauwels RA, Pedersen S, Busse WW, et al. Early intervention with budesonide in mild persistent asthma: a randomised, double-blind trial. Lancet 2003;361:1071-6

27 Price DB, Hernandez D, Magyar P, et al. Randomised controlled trial of montelukast plus inhaled budesonide versus double dose inhaled budesonide in adult patients with asthma. Thorax 2003:58:211-16.

28 Ringdal N, Eliraz A, Pruzinec R, et al. The salmeterol/fluticasone combination is more effective than fluticasone plus oral montelukast in asthma. Respir Med 2003;97:234-41

29 Vaquerizo MJ, Casan P, Castillo J, et al. Effect of montelukast added to inhaled budesonide on control of mild to moderate asthma. Thorax 2003:58:204-10.

30 Appleton SL, Adams RJ, Wilson DH, et al. Spirometric criteria for asthma: adding further evidence to the debate. J Allergy Clin Immunol 2005; 116:976-82

31 Lal S, Dorow PD, Venho KK, et al. Nedocromil sodium is more effective than cromolyn sodium for the treatment of chronic reversible obstructive airway disease. Chest 1993; 104:438-47.

32 Lemanske RF Jr, Sorkness CA, Mauger EA, et al. Inhaled corticosteroid reduction and elimination in patiehts with persistent asthma receiving salmeterol: a randomized controlled trial. JAMA 2001;285:2594-603.

33 Chalmers GW, Macleod KJ, Little SA, et al. Influence of cigarette smoking on inhaled corticosteroid treatment in mild asthma. Thorax 2002;57:226-30.

34 Chaudhuri R, Livingston E, McMahon AD, et al. Cigarette smoking impairs the therapeutic response to oral corticosteroids in chronic asthma. Am J Respir Crit Care Med 2003:168:1308-11.

35 Robson B, Woodman K, Burgess C, et al. Prevalence of asthma symptoms among adolescents in the Wellington region, by area and ethnicity. NZ Med J 1993;106:239-41

36 Crane J, Lewis S, Slater T, et al. The self reported prevalence of asthma symptoms amongst adult New Zealanders. NZ Med J 1994; 107:417-21.

37 D'Souza W, Lewis S, Cheng S, et al. The prevalence of asthma symptoms, bronchial hyperresponsiveness and atopy in New Zealand adults. NZ Med J 1999;112:198-202.

\section{BNF for Children 2006, second annual edition}

In a single resource:

- guidance on drug management of common childhood conditions

- hands-on information on prescribing, monitoring and administering medicines to children

- comprehensive guidance covering neonates to adolescents

For more information please go to bnfc.org 